\title{
RISCOS E EXPRESSÕES TERRITORIAIS DA CATÁSTROFE ANUNCIADA: CONTROVÉRSIAS E INCERTEZAS SOBRE MUDANÇAS CLIMÁTICAS
}

\section{RIESGOS Y EXPRESIONES TERRITORIALES DE CATÁSTROFE ANUNCIADA: CONTROVERSIAS E INCERTIDUMBRES SOBRE CAMBIO CLIMÁTICO}

\author{
RISKS AND TERRITORIAL EXPRESSIONS OF THE FORETOLD \\ CATASTROPHE: CONTROVERSIES AND UNCERTAINTIES ON CLIMATE \\ CHANGE
}

\section{Andrei CORNETTA ${ }^{1}$}

RESUMO: Com o objetivo de ressaltar o papel da ciência contemporânea, em especial das ciências atmosféricas, por meio da figura do Painel Intergovernamental sobre Mudanças Climáticas e de sua influência sobre a elaboração de políticas econômicas voltadas para as mudanças climáticas, discute-se neste artigo as dinâmicas de funcionamento desse órgão, bem como a atuação desse Painel vem legitimando uma série de normativas para a consolidação de um mercado internacional de emissões de gases efeito estufa. A abordagem é focada nas relações entre ciência e política e os riscos relacionados com as políticas internacionais sobre mudanças climáticas. Em particular, examina-se os riscos implícitos nas relações (distantes) entre especialistas e políticos.

Palavras-chave: ciência e política; mudanças climáticas antropogênicas; mercado de carbono; riscos e território.

RESUMEN: Con el fin de destacar el papel de la ciencia contemporánea, en especial las ciencias de la atmósfera, a través de la figura del Grupo Intergubernamental de Expertos sobre el Cambio Climático (IPCC) y su influencia en la elaboración de las políticas económicas sobre el cambio climático, este artículo describe la dinámica de su funcionamiento, así como el modo en que la actuación de este grupo de expertos legitima una serie de normas para la consolidación de un mercado internacional de emisiones de gases de efecto invernadero. El enfoque de este trabajo se centra en las relaciones entre ciencia y política y los riesgos relacionados con las políticas internacionales sobre el cambio climático. En particular, se examinan los riesgos implícitos en las relaciones entre los expertos y los políticos.

Palavras-clave: ciencia y políticas; cambio climático antropogenico; mercado de emisiones; riesgos y territorio.

\begin{abstract}
Aiming to highlight the role of contemporary science, particularly the atmospheric sciences, through the figure of the Intergovernmental Panel on Climate Change and its influence on the formulation of economic policies for climate change, this article discusses the dynamics the operation of this Panel and how it legitimatizes the consolidation of an international market for emissions of greenhouse gases. The approach is focused on the relationship between science and politics and the risks related to international policies on

\footnotetext{
${ }^{1}$ Mestre em Geografia e pesquiasador vínculado ao Laboratório de Geografia Agrária do Departamento de Geografia da Universidade de São Paulo (DG/USP). e-mail: andrei.cornetta@gmail.com
} 
climate change. The risks implicit in distant relationships between experts and politicians will be examined.

Keyword: science and politics; anthropogenic climate change; carbon market; risks and territory.

\section{INTRODUÇÃO}

Estamos entrando em uma 'nova era climática'. Assim estavam estampadas as principais manchetes dos jornais, após a divulgação do último relatório do Painel Intergovernamental de Mudanças Climática ${ }^{2}$ (IPCC, sigla em inglês). Além disso, publicavam os jornais, sobre os resultados da $9^{\mathrm{a}}$ Sessão do Grupo de Trabalho III do IPCC, realizada em maio de 2007 na cidade de Bancoc, que a principal conclusão dos cientistas era que "o aumento das emissões de gases de efeito estufa pode ser detido com custos relativamente baixos".

Estes, entre outros anúncios a respeito das mudanças climáticas, inspiram-nos a discutir sobre o papel da ciência na contemporaneidade. Neste artigo, portanto, pretende-se refletir sobre questões que permeiam a produção científica a respeito das mudanças do clima, mais precisamente sobre o papel do IPCC e sua superposição política em relação à adoção de medidas frente às mudanças globais do clima.

A acepção do termo "superposição" indica colocação por cima; aposição àquilo que se acrescenta; junção - a própria origem do IPCC atrelada ao âmbito das Nações Unidas e, como seu próprio nome indica (Intergovernmental Panel on Climate Change), nos remete a uma origem poligenética e de múltiplas determinações sociais. Sendo assim, para compreender o papel do IPCC, descartamos, antes de tudo, a idéia de uma produção científica autônoma, livre de juízo de valor, assentada em uma verdade universal, e a própria dualidade entre ciência e política.

Sem dúvida que o trabalho do IPCC, por sua característica híbrida, não poderia tratar a natureza e a política como domínios completamente separados. Entretanto, sua postura objetivista (uma ciência "feita em consenso") não possibilita um entendimento político mais amplo que abarque as relações profundas entre sociedade e o que se entende por "natureza".

\footnotetext{
${ }^{2}$ Durante a sua história, o IPCC publicou quatro "relatórios de avaliação". O último deles foi publicado em 2007 e apresentou comprovação científica de que a ação do homem interfere diretamente no equilíbrio climático do planeta. Disponível em: <www.ipcc.ch/publications_and_data/ar4/syr/en/contents.html>. Acesso em 30 abr. 2009.
} 
Sinteticamente, o IPCC apoia suas posições científicas sobre a tese das mudanças climáticas antropogênicas, atribuindo às emissões de gases efeito estufa como o grande responsável pelas mudanças globais no sistema climático. Essa tese, portanto, pressupõe uma escolha histórica, uma escolha política por se reproduzir e se relacionar com a natureza de determinada forma. Fato esse não considerado nos Relatórios do IPCC - a não ser as emissões de gases efeito estufa; todas quantificadas e, atualmente, convertidas em cifras.

Nas últimas décadas do século $\mathrm{XX}$, alguns acontecimentos passaram a dar maior amplitude à hipótese de mudanças globais do clima de influência antrópica. Em 1988 o climatologista James Hansen da NASA discursou para a comissão consultiva para a ciência do Senado dos Estados Unidos e afirmou que as causas das mudanças climáticas eram também antropogênicas ${ }^{3}$.

No mesmo ano, a então primeira-ministra britânica, Margareth Thatcher, reconheceu em pronunciamento na Royal Society a relevância do debate acerca das alterações do clima ${ }^{4}$. Vale destacar que no período de irrompimento das teorias neoliberais para as políticas de Estado, a Inglaterra de Thatcher passa a atuar fortemente nas políticas de mudanças globais do clima. A Inglaterra teve papel central nas negociações do Protocolo de Montreal de 1987, que discutiu os impactos dos clorofluorocarbonetos (CFC) na camada de ozônio. Tratou com a mesma seriedade as políticas de redução de emissões de $\mathrm{CO}_{2}$ e os incentivos à substituição das energias fósseis. Estes últimos, atrelados diretamente com as políticas de desarticulação sindical no país, em especial o sindicato dos mineiros, o que poderia ser parcialmente justificado pela questão ambiental (HARVEY, 2008: 185).

Nos anos de 1998 e 1999, os geofísicos Michael Mann, Raymond Bradley e Malcolm Hughes publicaram estudos de reconstruções dos padrões de temperatura global dos últimos seis séculos que demonstra uma elevação abrupta da temperatura a partir das primeiras décadas do século XX. Este estudo foi publicado na revista Nature ${ }^{5}$ e apresenta o gráfico que ficou conhecido como "hockey sticky" que demonstra essa elevação da temperatura terrestre. Estas análises, mais tarde foram incorporadas pelo IPCC na elaboração de seu Terceiro

\footnotetext{
3 Para uma leitura completa desse discurso, acessar: <http://image.guardian.co.uk/sysfiles/Environment/documents/2008/06/23/ClimateChangeHearing1988.pdf>. Acesso em 10 abr. 2012.

4 Ver: Margaret Thatcher. Speech to the Royal Society. 1988. Disponível em: <http://www.margaretthatcher.org/document/107346>. Acesso em 18 abr. 2012.

${ }^{5}$ Para a leitura completa desse artigo, ver: MANN; BRADLEY; HUGUES. Global-scale temperature atterns and climate forcing over the past six centuries. In: Nature. vol. 392. 1998. Disponível em: <http://www.geo.umass.edu/faculty/bradley/mann1998.pdf >. Acesso em 10 abr. 2012.
} 
Relatório de Avaliação (2001) e a partir daí a afirmação sobre mudanças globais do clima de origem antrópica passou a ter maior destaque nos meios de comunicação ${ }^{6}$.

Todavia, é necessário, também, não perder de vista as imbricações que este jogo político/científico voltado para as questões climáticas globais têm com as tecnologias e o mercado global. Santos (2002, p. 238) ressalta que as concepções de ciência, tecnologia e mercado global "devem ser encaradas conjuntamente e, assim, oferecer uma nova interpretação à questão ecológica, já que as mudanças que ocorrem na natureza também se subordinam a essa lógica".

Assim, a proposta aqui não é discutir sobre a "politização da ciência" (estas duas categorias não se separam por completo em sua constituição, tampouco em sua circulação social), mas, sobretudo na rede de ações sociais em que essa ciência se reproduz historicamente. Nesta perspectiva, a produção científica é sempre uma produção contextual e contingente, em que o saber científico é submetido a uma redefinição constante a partir das interações mútuas que se estabelecem numa "arena transcientífica" ou "transepistêmica", no sentido proposto pela socióloga austríaca Karin Knorr-Cetina (1982; 2005). A idéia de arena transcientífica remete-se à circulação social do produto científico na qual não se pode entendê-lo como "puramente" científico, tampouco como um saber maculado pela influência "estranha" da política.

Esta característica reforça o debate sobre os riscos relacionados às mudanças globais do clima. Não nos reportamos apenas às catástrofes climáticas que se anunciam nos Relatórios de Avaliação do IPCC e que se amplificam pela grande mídia, mas aos riscos implícitos nas relações (distantes) entre especialistas e políticos.

Enquanto objeto de produção e percepção social, o risco assinala a possibilidade futura de certos acontecimentos e processos e faz presente uma situação que (ainda) não existe. Os riscos em relação às mudanças climáticas estão ligados não apenas aos impactos na superfície terrestre, mas à própria relação indissociável que os mesmos têm com a política. Apesar de a origem de um órgão científico como o IPCC ter como elemento constitutivo a política sobretudo a de Estado -, o distanciamento entre os especialistas e os políticos se revela em

\footnotetext{
${ }^{6}$ Para uma leitura sobre a repercussão do tema das mudanças climáticas na imprensa, ver: BOYKOF, M. Balance as bias: global warming and the US prestige press. 2004. Disponível em: <http://www.eci.ox.ac.uk/publications/downloads/boykoff04-gec.pdf>. Acesso em 25 mar. 2012.

${ }^{7}$ Alguns trabalhos adotam essa abordagem e questionam se realmente as repostas que o IPCC aponta para as mudanças climáticas são neutras do ponto de vista científico ou se é política que se faz. Ver: TILIO NETO, P. Ecopolítica das mudanças climáticas: o IPCC e o ecologismo dos pobres, 2008; ONÇA, D. Curvar-se diante do existente: o apelo às mudanças climáticas pela preservação ambiental, 2007.
} 
um duplo sentido: tanto no aspecto epistemológico em relação à dualidade ciência e política, quanto na disparidade das escalas geográficas envolvidas.

Apesar da posição "oficial" e de estudos ${ }^{8}$ afirmarem a sua imparcialidade política, os relatórios do IPCC não encontram apoio unânime entre os cientistas no cenário internacional, sobretudo no que diz respeito à afirmação de que as atividades antrópicas, muito provavelmente, são responsáveis pelo que se vincula como "aquecimento global”.

No que tange aos resultados do IPCC em relação às mudanças físicas do clima, diversos estudos não apenas questionam sua legitimidade como indicam um cenário múltiplo ${ }^{9}$. É importante dizer que a diversidade de cenários não corresponde apenas às projeções futuras, mas, também, apóia-se em diferentes análises do clima pretérito e propõe outras adaptações necessárias diante das alterações climáticas.

O uso exacerbado de modelos computadorizados, dos valores médios, bem como de uma postura objetiva em relação aos cenários e projeções futuras, conduzem os relatórios do IPCC de uma leitura das mudanças climáticas para um "realismo" que é imposto não só aos formuladores de políticas, mas para toda a sociedade por meio da amplitude e da forma que os meios de comunicação abordam o tema.

Trata-se de uma postura que perdura desde a Revolução Científica ocorrida entre os séculos XVI e XVII. O perdurar, posto dessa forma, assume um duplo sentido para a ciência moderna: tanto no aspecto de sua longa duração, quanto na sua origem etimológica do 'fazer muito duro'. Este último, notadamente, reporta-se ao rigor científico aferido pelo rigor das medições - 'conhecer significa quantificar'. Entretanto, o primeiro sentido dessa perduração se anula por dentro, ou melhor, pelo segundo sentido que se reporta à ação rígida de uma racionalidade científica dominante. "É preciso refletir para medir", questiona Bachelard (2005) referindo-se aos obstáculos do conhecimento quantitativo e de sua característica principal do excesso de precisão. De acordo com Bachelard, essa se converte em uma das marcas mais nítidas do espírito não-científico, isto é, no momento em que as pretensões

\footnotetext{
${ }^{8}$ Este tipo de posicionamento pode ser visto em: MACHADO FILHO, H.. A Convenção-Quadro das Nações Unidas sobre mudanças climáticas e o Protocolo de Kyoto. In: KLINK (org.), 2007: pp. 21-75.

${ }^{9}$ Ver trabalhos de CONTI. Considerações sobre as mudanças climáticas globais. 2005; ESCARDO. Cambios en el sistema climático. Una aproximación al problema. 1990; GRAY, The Greenhouse Delusion. Critique of Climate Change 2001: The Scientific Basis. 2006; MARUYAMA, Aquecimento global?. 2009; MOLION, Efeitos dos vulcões no clima. 1994; SILVA DIAS. Mudanças climáticas; como conviver com as incertezas sobre os cenários futuros. 2005; entre outros.
} 
científicas se assentam em premissas objetivas, o conhecimento se distancia da realidade: "O cientista crê no realismo da medida mais do que na realidade do objeto" (Idem, p. 262).

Basicamente, no cenário atual sobre mudanças globais do clima, existem duas correntes científicas bem definidas, que apresentam argumentos distintos. A primeira ressalta a ação antrópica desde o início da era industrial como responsável pela intensificação das emissões de $\mathrm{CO}_{2}$ na atmosfera. Do outro lado, argumentam que não há conhecimento científico suficiente sobre as dinâmicas do clima capaz de sustentar a primeira posição, ou seja, a "oficial". Entretanto, há ainda a posição dos chamados "céticos" que criticam os resultados apresentados pelo IPCC, sobretudo em relação às afirmativas de uma possível mudança climática de origem antropogênica. Diversos estudos propõem uma perspectiva de análise alternativa ao IPCC e consideram, por exemplo, a influência de fenômenos extraterrenos como manchas solares (MOLION, 1994, 2001; MARUYAMA, 2009), e raios cósmicos (STOZHKOV et al., 2000; MEWALD, 2009) na variabilidade climática do planeta. Stozhkov, físico russo ligado ao programa Cosmics Leaving Outdoor Droplets (Cloud), do Centro Europeu de Pesquisas Nucleares, estuda como a atividade solar, mais especificamente, como os fluxos de raios cósmicos estão conectados a fenômenos elétricos, como a formação de nuvens baixas.

De acordo com ele, o aumento da radiação solar na atmosfera pode acelerar a formação de aerossóis, ou grupos de moléculas, que se aglutinam e compõem a base da formação de gotículas nas nuvens. Com a intensificação desse processo o percentual de reflectância de luz solar torna-se mais eficiente e mais estável, produzindo um efeito contrário do anunciado pelos relatórios do IPCC, ou seja, uma variabilidade do clima global tendendo para o resfriamento (STOZHKOV et al., 2000).

Para o meteorologista brasileiro Luis Molion (1994; 2001), o resfriamento climático na escala global - considerando as eras glaciais nos últimos dois milhões de anos - tem como base as variações dos parâmetros orbitais da Terra, a variabilidade energética do Sol, bem como o aumento do albedo planetário devido à intensidade de vulcanismos por longos períodos. Nesse sentido, o autor ressalta que as emissões vulcânicas de enxofre, carbono e aerossóis podem contribuir para o resfriamento da troposfera. Basicamente existem dois tipos de vulcões: os difusos, que lançam continuamente lavas, cinzas e gases, que afetam o ambiente em escala local; e os explosivos, que conseguem lançar material particulado e dióxido de enxofre diretamente na estratosfera, afetando o clima em escala global (MOLION, 1994, p. 14). 
Shigenori Maruyama, compartilha de uma perspectiva semelhante e ressalta que as atividades da atmosfera, da hidroesfera e da biosfera são determinadas pela energia do Sol. A decorrência de uma grande produtividade de magma por atividade vulcânica, por exemplo, vai originar cinzas vulcânicas e, "ao atingir a estratosfera, envolverá a superfície terrestre e, assim, atuará na obliteração da energia solar, impulsionando o esfriamento da Terra" (MARUYAMA, 2009, p. 47). O geólogo japones exemplifica este fenômeno com a erupção de 1991, associado ao Vulcão Pintubo, nas Filipinas que exerceu grande influência sobre o clima da Terra. A erupção ininterrupta do magma, "com cinzas vulcânicas lançadas a 25 e 35 km, fez com que o aerossol composto de minúsculas partículas sólidas permanecesse na estratosfera". Esse fato, segundo Maruyama,

obliterou a energia solar e diminuiu a intensidade das radiações que atingem a Terra $\mathrm{e}$, durante dois anos, a temperatura média diminuiu de 0,5 a $0,8^{\circ} \mathrm{C}$. A influência foi tão grande que chegou a anular o efeito dos gases efeito estufa, como o produzido pelo $\mathrm{CO}_{2}$ total de origem antrópica $(200 \mathrm{ppm})$, correspondente à emissão de 200 anos (Idem, p. 120).

Questões mais pontuais como o processo de savanização da floresta amazônica, reconhecidas pelo IPCC como consequência do "aquecimento global", são importantes exemplos de um tema sobre o qual não há concordância em relação aos efeitos das mudanças do clima. Em entrevista concedida à revista Fórum poucos meses após os resultados do último relatório do IPCC, o geógrafo Aziz Ab'Saber fez duras críticas em relação aos resultados do Painel. Sobre o fenômeno da savanização da floresta amazônica, Ab' Saber diz:

É porque eles ficam dizendo que quando o mar subir vai destruir a Amazônia e entrar o cerrado etc. Não sabem de nada, são pessoas da Física, engenheiros e outros [...]. Mesmo porque, quando o mar estava mais alto três metros, não destruiu a floresta, pelo contrário, houve mais evaporação, mais calor e mais umidade para a Amazônia e muito mais para o Brasil Tropical-Atlântico, sem o que, aqueles redutos de mata, que resistiam apesar do clima frio, não teriam se ampliado e se emendado. É a teoria dos redutos e refúgios. Tenho moral para falar isso, porque sou autor da teoria dos redutos e o [Paulo] Vanzolini da dos refúgios (Revista Fórum, jul. 2007).

Além disso, Ab'Saber chama a atenção para aspectos que não são considerados pelos relatórios do IPCC, como as formas de devastação promovidas diretamente pelo homem: "São 500 quilômetros quadrados somados de devastação da Amazônia. É equivalente a duas vezes o estado de São Paulo. Não tem sentido falar das mudanças climáticas e esquecer do que os homens estão fazendo, 'savanizando' tudo” (Idem). 
De acordo com o próprio Aziz Ab’Saber, “é claro que está havendo mudanças no clima!”. Entretanto, o professor ressalta que suas razões são diferentes das do IPCC e chama a atenção para fenômenos como o "metabolismo urbano", o "domo de poluição", a "periodicidade climática", entre outras questões que não são tão bem explicitadas pelo IPCC e que também possuem grande potencial para interferir no comportamento do clima global.

Em artigo publicado pela Revista do Departamento de Geografia da USP, José Bueno Conti, destaca o papel do vapor d'água no processo do aquecimento do planeta. De acordo com Conti:

\begin{abstract}
A maioria dos eventos que trata do assunto e os inúmeros textos que se publicam a respeito, surpreendentemente, não avaliam, de forma adequada, o papel do vapor d'água no processo de aquecimento do planeta, superestimando, no nosso entender, a responsabilidade dos gases produzidos pela ação antrópica, os quais, como vimos, têm, percentualmente, uma participação menor ${ }^{10}$ (CONTI, 2005, p. 73).
\end{abstract}

Nesse sentido, o geógrafo conclui que há muitas perguntas para as quais ainda não se têm respostas satisfatórias. Cita diversos estudos, como o dos professores Giorgio Giacaglia e Pedro Leite da Silva Dias, ambos do Instituto Astronômico e Geofísico da USP, nos quais é indicado que em alguns pontos vêm se registrando o oposto das evidências do "aquecimento global", ou seja, uma tendência negativa das médias térmicas ao longo de décadas, provavelmente em função de fatores locais.

Em concordância com Conti, acreditamos que a questão das mudanças climáticas precisa, portanto, "passar por uma apreciação mais refinada a fim de que se possa determinar, com maior consistência, o papel da natureza e da ação humana no processo, mesmo porque as duas esferas podem atuar de forma solidária e intercambiar influências" (Idem, p. 74). As controvérsias, bem como as abordagens relacionadas ao tema, são diversas e exigem aprofundamentos que não pode ser reduzido a um "consenso" científico.

Grande parte das pesquisas (ao menos as de maior visibilidade) concentra seus esforços em estudos que buscam entender os efeitos dos gases efeito estufa na atmosfera e olvidam-se das características múltiplas que definem o clima em suas diferentes escalas; fatores que vão desde o ciclo das manchas solares, o efeito das erupções vulcânicas, as

\footnotetext{
${ }^{10}$ Conti (2005, p. 73) refere-se à composição física do efeito estufa sem o qual a temperatura média do planeta, hoje em torno de $15^{\circ} \mathrm{C}$, desceria para $-18^{\circ} \mathrm{C}$, tornando inviável a permanência da biosfera tal como hoje a conhecemos e este efeito não resulta somente de gases produzidos pela atividade humana. Estes contribuem com apenas $40 \%$ do total, cabendo ao dióxido de carbono $25 \%$ e $15 \%$ aos demais. É o vapor d'água, com $60 \%$ de participação, o agente mais ativo do efeito estufa, presente em diferentes faixas de absorção da radiação infravermelha (onda longa), colaborando de forma preponderante no processo de aquecimento planetário, e seu volume na atmosfera independe da ação humana.
} 
alterações do campo magnético e da órbita terrestre, além das múltiplas intervenções das sociedades (SANT'ANNA, 2003).

Nesse painel as perguntas se multiplicam e tornam-se mais complexas em um enredo ${ }^{11}$ de relações que extrapolam os domínios científicos. $O$ fenômeno que se engendra cientificamente ganha amplitude e o que se encontra é um emaranhado de ação/cognição no qual já não se pode mais aplicar adequadamente a ideia preconcebida de uma teoria científica (KNORR-CETINA, 2005, p. 60). Assim como na multiplicidade de informações e pesquisas científicas que apontam para as mudanças climáticas antropogênicas, seja apenas pelas emissões de gases efeito estufa ou em decorrência das diversas interações entre sociedade e natureza, as incertezas pairam também quanto aos procedimentos propostos de adaptação e reorganização espacial diante das mudanças do clima. Nesse sentido, os riscos são imanentes a esse processo em duas direções: 1) pelas próprias consequências das mudanças físicas que o processo de mudanças do clima pode acarretar na superfície terrestre; 2) por conta da relação indissociável que os riscos têm com a política.

\section{LUGAR DE RISCOS: CONTROVÉRSIAS E INCERTEZAS SOBRE MUDANÇAS DO CLIMA}

Tomar decisões competentes ao território, à repartição dos bens, ao uso dos recursos equivale a, pelo menos em parte, como sugere Veyret (2007: 29), "fazer apostas sobre o futuro, a construir perspectivas que encerram sempre uma dose de riscos". A relação do risco com o território é contingente e contextual, isto é, as possibilidades de concretização de uma catástrofe ou o anúncio de um perigo estão diretamente associadas ao seu contexto histórico, bem como a forma que se configura a ocupação territorial.

Sem dúvida, as questões que orbitam os riscos envolvem noções de objetividade, subjetividade e objetivação. Não se pode dizer que um risco seja puramente fabricado socialmente, tampouco que se dê objetivamente na realidade. A objetivação, isto é, o processo por meio do qual as ações humanas concretizam-se em objetos espaciais, são fundamentais para a forma que se projetam os riscos - sejam eles considerados naturais ou decorrentes de atividades antrópicas.

\footnotetext{
11 As diferentes acepções de enredo expressam sinteticamente a complexidade do contexto: 1. Episódio complicado, confuso; mistério, segredo; 2. sucessão de acontecimentos que constituem a ação; 3 . informação falsa ou controvertida; mentira. Variantes: argumento, entrecho, fábula, fabulação, intriga, teia, trama, urdidura.
} 
Além disso, como Natenzon et al. (2003, pp. 259; 260) ressalta, é de fundamental importância compreender a origem que se atribui aos riscos. Ou seja, a partir do momento em que os riscos passam a ser explicados pela sua origem e não pelo seu processo, cede-se lugar à "naturalização" do fenômeno, tirando o foco de questões reflexivas e subjetivas do caso, e, dessa forma, desprendendo-o de suas conotações sociais. A origem dos inúmeros riscos que se atribuem às mudanças do clima, no limite, reduz-se às emissões de gases efeito estufa em sua acumulação histórica desde a Primeira Revolução Industrial.

Apesar da centralidade dos "riscos" para o debate das mudanças climáticas propriamente, o Grupo de Trabalho II do IPCC, que tem seus trabalhos orientados para "o entendimento científico atual dos impactos da mudança do clima nos sistemas naturais, manejados e humanos, a capacidade de adaptação desses sistemas e sua vulnerabilidade", não oferece um lugar de destaque ao termo (ao menos para sua conceituação) em nenhum de seus quatro relatórios e glossários que acompanham os documentos ${ }^{12}$. Em geral, a palavra "risco" aparece associada aos impactos que supostamente as mudanças globais do clima (de origem antrópica) poderiam acarretar, tais como: os possíveis riscos de elevação do nível do mar aos sistemas costeiros, os aumentos de temperatura e as inúmeras decorrências de ondas de calor e mesmo impactos econômicos em indústriais, infraestruturas, agricultura, etc. (IPCC, 2007a).

Diversos estudos acerca da construção social dos riscos, com orientações teóricas das mais variadas, têm demonstrado uma grande utilidade analítica para a compreensão dos desastres e a forma que estes impactam as sociedades. Inúmeras instituições de pesquisa têm se dedicado aos estudos sobre riscos e à forma como estes são percebidos socialmente: desde os geógrafos estadunidenses da década de 1920 que discutiram os chamados natural hazards $^{13}$, passando pelas concepções sociológicas, como a modernização reflexiva e a "sociedade de risco" de Beck $(1998 ; 2008)$, a escola francesa marcada pelas obras La société vulnerable ${ }^{14}$ e Sociologe du risque $e^{15}$, ambas com uma abordagem associativa entre construção social e percepções do risco, até estudos mais recentes que têm surgido na América Latina com destaque para la Red de Estudios Sociales em Prevención de Desastres (La Red),

\footnotetext{
${ }^{12}$ Os glossários e documentos do IPCC, todos divulgados nas línguas oficiais da ONU, não apresentam a palavra risco, bem como nenhuma tradução que se equivalha. Tampouco, conceitos próximos como natural hazards, amplamente divulgado na língua inglesa, como nos sugere Monteiro (1991). Ver: <http://www.ipcc.ch/publications_and_data/publications_and_data_glossary.htm>. Acessado em 15 mai. 2009.

${ }^{13}$ Sobre o tema, ver: HOGAN; MARANDOLA Jr., Riscos e perigos: o estudo geográfico dos natural hazards. 2004; MONTEIRO, Clima e excepcionalismo. Conjecturas sobre o desempenho da atmosfera como fenômeno geográfico. 1991: ii; 9.

${ }^{14}$ FABIANI, J. L. \& J. THEYS (edits). La Société Vulnérable - évaluer et maitriser les risques. 1987.

${ }^{15}$ PERETI-WATEL, P. Sociologe du risque. 2000.
} 
algumas pesquisas vinculadas ao Programa de Investigaciones em Recursos Naturales y Ambiente (PIRNA) da Universidade de Buenos Aires, o Núcleo de Estudos de Pesquisas Sociais em Desastres (NEPED) da Universidade Federal de São Carlos, dentre outras ${ }^{16}$.

Os relatórios do IPCC - em sua política/ciência objetivista - valorizam atividades que compensam o excesso de carbono na atmosfera em detrimento de um entendimento social sobre riscos. Isto é, não há uma preocupação epistemológica por parte do IPCC (e consequentemente dos que o seguem) em abordar de forma mais ampla os distintos processos sociais (que não apenas as emissões) e suas correlações com as mudanças do clima. O que se encontra, sobretudo nos relatórios do GT II, é a concepção de hedging - algo próximo de ponderación de los riesgos em espanhol ou em francês couverture -: In the context of climate change mitigation, hedging is defined as balancing the risks of acting too slowly against acting too quickly, and it depends on society's attitude towards risks ${ }^{17}$. Para o IPCC, tanto adaptação como mitigação são consideradas práticas capazes de atenuar os impactos que as mudanças do clima podem acarretar na superfície terrestre.

É importante ressaltar que os recursos destinados às mudanças climáticas encontramse mal distribuídos e canalizados para projetos mitigatórios que envolvem uma série de "novas" mercadorias e que não se restringem apenas à comercialização de Reduções Certificadas de Carbono ${ }^{18}$. No caso específico das mudanças climáticas, os recursos também se distribuem geograficamente de maneira desigual: "Destinam-se mais recursos para reduzir as emissões (mitigação) e menos para enfrentar os efeitos da mudança climática que atingem todos os países (adaptação)" (AYMA, 2008).

Exemplo disso é o potencial de geração de créditos de carbono que China e Índia oferecem para o primeiro período do Protocolo de Kyoto (2008-2012) - 72\% dos totais de Reduções Certificadas de Carbono geradas no mundo. Esse potencial deve-se ao fato de os dois países terem uma amplitude maior para impulsionar "destruições criativas". Em outras palavras, a matriz energética desses dois países é baseada na queima de combustíveis fósseis em termelétricas, o que garante uma expectativa maior de remodelamentos no setor.

\footnotetext{
16 Além dessas instituições vinculadas ao debate acadêmico, há inúmeros órgãos atrelados ao âmbito intergovernamental como a própria Secretaria de Estratégia Internacional para a Redução de Desastres (ONU/EIRD). Ver: <http://www.eird.org/index-esp.html>. Acessado em 17 set. 2009.

17 Ver: IPCC. Glossary Intergovernmental Panel on Climate Change. 2001, p. 11. Disponível em: <http://www.ipcc.ch/publications_and_data/publications_and_data_glossary.htm>. Acesso em 02 mai. 2009.

${ }^{18}$ Os países industrializados há mais tempo e que ratificaram o Protocolo de Quioto em 1997 podem comprar nos mercados ad hoc Reduções Certificadas de Carbono (também conhecido como créditos de carbono) gerados por projetos nos países em desenvolvimento e utilizá-los no cumprimento de suas metas de redução de emissões de gases efeito estufa.
} 
Isso ratifica o contra-senso que existe neste mercado; pois os setores que mais se beneficiam dos programas relacionados às mudanças climáticas são os que mais poluem. Entretanto, nem sempre os projetos mitigatórios, sobretudo as experiências que temos acompanhado aqui no Brasil, se manifestam de maneira eficaz de um ponto de vista socioambiental $^{19}$. A orientação desses projetos acompanha o entendimento científico que se dá às mudanças do clima por parte do IPCC e demais órgãos ligados a ONU - isto é, a preocupação é reduzida à ideia fixa em diminuir a emissão de gases efeito estufa e aos mecanismos capazes de neutralizá-los ou compensá-los.

\section{MECANISMOS DE DESENVOLVIMENTO LIMPO E CONFLITOS LOCAIS: O CASO PLANTAR}

O Grupo Plantar S.A. é criado em 1967 a partir do advento de políticas de estímulo ao reflorestamento quando se institui, em 1966, o Fundo de Investimento Setorial - FISET Reflorestamento. Em meados de 1980, a reflorestadora adentra ao mercado de ferro gusa e passa a produzir o subproduto em Sete Lagoas, Minas Gerais, a $100 \mathrm{~km}$ de seus reflorestamentos (CHANG, 2004). Além de seu braço siderúrgico, a empresa atualmente flexibiliza seus negócios com gestão ambiental, produção de amaru - "a madeira imunizada" - árvore geneticamente modificada, dotada de alta resistência e imune a organismos xilófagos (cupins, fungos, bactérias) - e, mais recentemente, no mercado de carbono com atividades de $\mathrm{MDL}^{20}$. De acordo com o site da empresa, "são objetivos do Projeto Plantar de créditos de carbono, produzir o ferro primário mais limpo do planeta, por meio do uso de biomassa plantada, de acordo com rigorosos princípios sociais e ambientais, e gerar créditos de carbono de acordo com o Mecanismo de Desenvolvimento Limpo" (grifo nosso). O uso de biomassa plantada, no caso, refere-se a grandes extensões de monocultivos de eucaliptos ${ }^{21} \mathrm{em}$

\footnotetext{
19 Para que um projeto de MDL possa ser validado é necessário comprovar não apenas a redução ou compensação de gases efeito-estufa, mas os benefícios socioambientais associados ao projeto. Segundo o Anexo III da Resolução $n^{\circ} 1$ da Comissão Interministerial de Mudança Global do Clima, os participantes do projeto deverão descrever como a atividade de projeto contribuirá para o desenvolvimento sustentável local, desenvolvimento de trabalho e a geração líquida de empregos e distribuição de renda. Disponível em: <www.mct.gov.br/upd_blob/2736.pdf>. Acessado em 30 mai. 2009.

${ }^{20}$ Os denominados MDL são os únicos instrumentos de mercado criados para gerar créditos compensatórios de gases efeito estufa que competem aos países em desenvolvimento. A partir de uma série de exigências técnoburocráticas, o projeto de MDL é submetido a uma análise e considerado elegível (ou não) para gerar Reduções Certificadas de Carbono e comercializa-las nos mercados ad hoc.

21 "Cada árvore de eucalipto pode sequestrar até $20 \mathrm{~kg}$ de gás carbônico por ano. Um hectare de floresta jovem sequestra, em média, 35 toneladas de $\mathrm{CO} 2$ por ano. Por outro lado, o consumo de água do eucalipto varia de 800 a 1,2 mil litros por metro quadrado. Isso significa que para produzir um quilo de madeira da planta são
} 
áreas que abrangem os municípios de Curvelo, Felixlândia e São João do Buriti, norte de Minas Gerais. A lógica compensatória é evitar a conversão vegetal para o carvão mineral (coque) na siderurgia do ferro gusa e plantar eucaliptos para se autoabastecer de matériaprima energética.

Este Grupo que detém atividades certificadas por selos como Forest Stewardship Council (FSC), Empresa Amiga da Criança (Fundação Abrinq) e que tem seu projeto de MDL financiado pelo The World Bank Prototype Carbon Fund (PCF) é o mesmo que solapa a água e reduz as potencialidades paisagísticas dos referidos municípios situados em domínios de chapadões recobertos por cerrados. Paisagem esta que foi imortalizada no universo roseano se abafa hoje em uma monotonia geométrica de eucaliptos. O projeto se desenvolve em 23.000 hectares de florestas plantadas, sendo apenas parte de um montante de 100.000 ha no estado de Minas Gerais dos quais a Plantar é proprietária.

O excelente documentário The Carbon Connection, retrata bem as consequências deste projeto no cotidiano de duas comunidades: de um lado, a comunidade de São José do Buriti, e de outro, a comunidade de Grangemouth na Escócia, vizinha das refinarias da British Petroleum (BP), firma que compra/compensa parte de suas emissões com os créditos de carbono gerados pelo projeto Plantar. O filme mostra por meio de uma videoconferência entre as duas comunidades os diversos impactos que ambas sofrem. Em São José do Buriti, os impactos que decorrem das plantações de eucalipto passam pela diminuição do volume de água (em alguns casos o assoreamento) de riachos e córregos que abasteciam famílias, redução das áreas de veredas e biodiversidade, sem contar as ameaças sofridas por parte de quem protesta e resiste. No outro hemisfério, as consequências não são menores: doenças respiratórias, contaminação de corpos d'água, poluição visual e auditiva são apenas alguns dos impactos imediatos que as refinarias da BP provocam na comunidade de Grangemouth.

Como bem apreende o filme, "as duas comunidades estão agora ligadas pela pesada carga que lhes impõe o novo mercado de emissões". Quais os verdadeiros riscos das mudanças climáticas? Caberia contabilizar estes impactos nos créditos de carbono? Quais as vulnerabilidades sociais envolvidas neste processo? 


\section{CONSIDERAÇÕES SOBRE RISCOS SOCIAIS E MUDANÇAS CLIMÁTICAS}

Os riscos são passíveis de serem concebidos no interior de uma dinâmica contraditória que articula sujeitos e escalas geográficas segundo lógicas diversas. Neste sentido, Vayret (2007), ressalta a associação estratégica entre dois sujeitos principais: os especialistas e os políticos. Estes últimos estão no centro das decisões; de fato, “eles devem fornecer respostas à sociedade civil apoiando-se no conhecimento dos especialistas". É fundamental ressaltar que nessa abordagem sempre há uma defasagem entre o grau de gravidade estabelecido pelos especialistas, o reconhecimento pelos políticos gestores e o risco absorvido pelas pessoas na sociedade em geral. O risco (e nesse caso, riscos é que não faltam em relação às mudanças climáticas) para ser considerado pelos políticos deve ser calculável, avaliável. Entretanto, como a geógrafa francesa argumenta, "a partir do momento em que o cálculo probabilístico atinge seu limite, a noção de risco perde sua pertinência e entra-se no domínio da incerteza" (Idem, p. 30).

$\mathrm{O}$ risco, enquanto categoria social deve ser entendido de acordo com as especificidades de cada sociedade - com suas normas, valores, crenças, estrutura política, socioeconômica e jurídica (NATENZON, 2003: 259). Neste ponto, ressalta-se a importância do conceito de "vulnerabilidade social" para uma compreensão mais apurada dos possíveis riscos que podem impactar os territórios. Sem o uso deste conceito, chama atenção Beck (2008: 242), o discurso sobre os perigos ambientais globais é esvaziado.

De acordo com o sociólogo alemão, "vulnerabilidade social é um conceito coletivo que abarca os meios e possibilidades de que dispõem (ou não) os indivíduos, as comunidades ou grupos inteiros para acabar com os riscos e as inseguranças (sociais) que os ameaçam" (Idem). Notadamente, quanto mais desprovido de estruturas, recursos econômicos, bem como de opções políticas, maior será o grau de vulnerabilidade de um território, de uma dada porção espacial, de um grupo social determinado.

Neste ponto, constata-se o descolamento que há entre as tomadas de medidas no âmbito internacional em relação às mudanças climáticas e os territórios, pois este movimento pressupõe, conforme mencionado acima, um distanciamento entre os especialistas e os políticos que são responsáveis por aplicarem as diretrizes instituídas internacionalmente nos territórios. 
Para Santos (2000, p. 82), “a integração do local e do global é vertical, dependente e alienadora, já que muitas decisões essenciais concernentes aos processos locais são estranhas ao lugar, pois obedecem a motivações distantes". O autor completa afirmando que, nessas condições, a tendência é que prevaleçam os interesses corporativos sobre os públicos, no que diz respeito à evolução do território, da economia e das sociedades locais (Idem, p. 107).

Entendemos, assim, que o conjunto de transformações vindas com o contexto atual das mudanças globais do clima, justifica a necessidade de reflexões mais aprofundadas em relação às posições adversas que o tema suscita neste início de século XXI. Além disso, reconhecemos a importância desta discussão no interior da ciência geográfica, tendo em vista a sua contribuição para o entendimento das relações indissociáveis entre economia, política e clima em seus desdobramentos espaciais.

\section{REFERÊNCIAS BIBLIOGRÁFICAS:}

AYMA, E. M. Cambio climático: Salvemos al planeta del capitalismo. 28 nov. 2008. La Paz: Ministerio de Medio Ambiente y Agua (MMAyA). Disponível em: <www.mmaya.gob.bo/documentos/suplementomedioambiente.pdf>. Acesso em 13 abr. 2009.

BACHELARD, G. A formação do espírito científico. Rio de Janeiro: Contraponto, 2005.

BECK. U. La sociedad del riesgo mundial. En busca de la seguridad perdida. Barcelona: Paidós, 2008.

CHANG, M.Y. Seqüiestro de carbono florestal no Brasil: dimensões políticas, socioeconômicas e ecológicas. São Paulo: Annablume, 2004.

CONTI, J. B. Considerações sobre as mudanças climáticas globais. São Paulo: Revista da Associação Nacional de Pesquisa e Pós-Graduação em Geografia (ANPEGE). n ${ }^{\circ}$ 2/. pp. 81-88. 2005.

HARVEY, D. O neoliberalismo. História e implicações. São Paulo: Loyola, 2008.

INTERGOVERNMENTAL PANEL ON CLIMATE CHANGE (IPCC). Mudança do Clima 2007: Impactos, Adaptação e Vulnerabilidade. Sumário para os Formuladores de Políticas: Quarto Relatório de Avaliação, Grupo de Trabalho II. 2007a.

Mudança do Clima 2007: Mitigação da Mudança do Clima. Sumário para os Formuladores de Políticas: Quarto Relatório de Avaliação do IPCC, Grupo de Trabalho III. 2007b.

Procedures for the preparation, review, acceptance, adoption, approval and publication of IPCC reports: Appendix A to the Principles Governing IPCC Work. Disponível em: <http://www.ipcc.ch/pdf/ipcc-principles/ipcc-principles-appendix-a.pdf>. Acesso em 27 set. 2009. 
KNORR-CETINA, K. Scientific comunities or transepistemic arenas of research? A critique of quase-economic model of science. In: Social studies of science. vol. 12, n 1, pp. 101-130, fev.1982.

La fabricación del conocimiento. Um ensayo soble el carácter constrictivista y contextual de la ciencia. Buenos Aires: Universidad Nacional de Quilmes Editorial, 2005.

MOLION, L. C. B. Efeitos de vulcões no clima. Caderno de Geociências, n 12, p. 13-24, out./ dez., 1994.

MONTEIRO, C. A. de F. Clima e excepcionalismo. Clima e excepcionalismo. Conjecturas sobre o desempenho da atmosfera como fenômeno geográfico. Florianópolis: Editora da UFSC, 1991.

NATENZON, C. E. et al. Las dimensiones del riesgo en ámbitos urbanos. Catastrofes en el area metropolitana de Buenos Aires. In: BERTOCELLO, R; CARLOS, A.F.A. (orgs). Processos territoriales en Argentina y Brasil. Buenos Aires: Instituto de Geografia, Facultad de Filosofia y Letras, Universidad de Buenos Aires, 2003.

ROCHADELLI, R. A estrutura de fixação dos átomos de carbono em reflorestamentos. Tese (Doutorado em Ciências Florestais) - Setor de Ciências Agrárias, UFPR, Curitiba, 2001.

SANT'ANNA NETO, J. L. Da complexidade física do universo ao cotidiano da sociedade: mudança, variabilidade e ritmo climático. Terra Livre, São Paulo: ano 19, v. I, n. 20, p. 5163, jan-jul. 2003.

SANTOS, M. Por uma outra globalização. São Paulo: Record, 2000.

.A natureza do espaço. São Paulo: Edusp, 2004.

STOZHKOV, Y.; POKREVS, P.; OKHLOPK, V. P. Long-term negative trend in cosmic ray flux. Journal of geophysical research. Vol. 105, $\mathrm{n}^{\circ}$ A1, pp. 9-17, jan. 2000.

VEYRET, Y. Os Riscos: o homem como agressor e vítima do meio ambiente. São Paulo: Contexto, 2007. 